\title{
PENGARUH KONSELING FAKTOR RISIKO KEHAMILAN TERHADAP KEMAMPUAN DETEKSI DINI DAN PERSIAPAN PERSALINAN DI KABUPATEN TASIKMALAYA
}

\section{THE INFLUENCE OF RISK FACTORS CONCELLENCE ON EARLY DETECTION ABILITY AND LABOR PREPARATION IN TASIKMALAYA DISTRICT}

\author{
Dede Gantini ${ }^{1 *}$, Sinar Pertiwi ${ }^{2}$ \\ 1,2Poltekkes Kemenkes Tasikmalaya, Indonesia \\ email: ${ }^{*}$ ddgianti@gmail.com, ${ }^{2}$ ateubdg@gmail.com
}

\begin{abstract}
ABSTRAK
Upaya percepatan penurunan Angka Kematian lbu berfokus pada deteksi dini, penanganan dan rujukan kehamilan. Pendekatan risiko pada ibu hamil merupakan strategi operasional dalam upaya pencegahan terhadap kemungkinan kesakitan atau kematian melalui peningkatan efektifitas dan efisiensi dengan memberikan pelayanan yang lebih intensif kepada risiko ibu hamil dengan cepat serta tepat, agar keadaan gawat ibu maupun bayi dapat dicegah. Upaya meningkatkan kualitas pelayanan kebidanan juga ditentukan oleh keterampilan bidan untuk berkomunikasi secara efektif dan melakukan konseling yang baik kepada klien. Melalui konseling diharapkan ibu hamil memahami kondisinya dan dapat menentukan tempat persalinan sehingga dapat melakukan persiapan persalinan dan upaya pencegahan komplikasi dengan tepat.Tujuan penelitian untuk mengetahui pengaruh konseling faktor risiko kehamilan terhadap kemampuan Ibu hamil dalam melakukan deteksi dini dan persiapan persalinan di Wilayah Dinas Kesehatan Kabupaten Tasikmalaya tahun 2018. Desain penelitian analitik korelatif 2 kelompok berpasangan. Penelitian dilaksanakan di Puskesmas Cikatomas dan Puskesmas Cisayong pada bulan Juni-Juli 2018. Sampel penelitian adalah ibu hamil berjumlah 30 orang. Teknik pengumpulan datamenggunakan kuesioner. Analisis data menggunakan uji $t$ dan uji Wilcoxon. Hasil penelitian terdapat pengaruh yang signifikan konseling faktor risiko kehamilan terhadap kemampuan deteksi dini kehamilan berisiko dan persiapan persalinan lbu hamil di wilayah Dinas Kesehatan Kabupaten Tasikmalaya Tahun 2018. Saran agar kebijakan penapisan risiko kehamilan dilaksanakan dilapangan dan menjadi prosedur tetap karena sangat membantu proses pelaksanaan kegiatan rujukan terencana
\end{abstract}

Kata Kunci: deteksi dini, konseling, persiapan persalinan, risiko kehamilan

\begin{abstract}
Efforts to accelerate the reduction of maternal mortality rates focus on early detection, treatment and referral of pregnancy. The risk approach in pregnant wome is an operational strategy in an effort to prevent the possibility of morbidity or death through increasing effectivenessand efficiency by providing more intensive services to the risksof pregnant women quickly and precisely, so that the situation of maternal and infant health can be prevented.
\end{abstract}


Efforts to improve the quality of midwifery services are also determined by the skills of midwives to communicate effectively and provide good counseling to clients. Through counseling, it is expected that pregnant women understand their condition and can determine the place of delivery so they can make childbirth preparations and efforts to prevent complications appropriately. The aim of the study was to determine the effect of counseling on pregnancy risk factors on the ability of pregnant women to carry out early detection and preparation for labor in the Tasikmalaya District Health Office Region in 2018. Design correlative analytic studies in 2 groups in pairs. The study was conducted at Cikatomas Health Centes and Cisayong Health Center in June-July 2018. The study sample was 30 pregnant women. The technique of collecting data using a questionnaire. Data analysis using t test and Wilcoxon test. The results of the study showed that there was a significant effect of counseling on pregnancy risk factors on the ability of early detection of risky pregnancies and childbirth preparation for pregnant women in the Tasikmalaya District Health Office area in 2018. Suggestions that the pregnancy risk screening policy be carried out in the field and become a fixed procedure because it greatly assists the implementation of planned referral activities.

\section{Keyword: counseling, delivery preparation, early detection, risk og pregnancy}

\section{PENDAHULUAN}

Upaya yang dilakukan untuk mencapai target SDGS yaitu AKI < 100 per 100.000 kelahiran hidup, angka kematian neonatal < 9/1000 kelahiran hidup dan angka lahir mati < 7 per 1000 kelahiran total. Pemerintah telah melaksanakan berbagai strategi. Salah satu strategi yang akan dilakukan adalah meningkatkan kualitas pelayanan kesehatan ibu serta adanya kesinambungan dan integrasi pelayanan kesehatan ibu. ${ }^{1}$

Penyebab kesakitan ibu/ morbiditas di Indonesia meliputi penyebab langsung kematian ibu di dominasi oleh perdarahan, hipertensi/eklamsi dan infeksi, sedangkan penyebab tidak langsung masih banyak kasus 3 terlambat dan 4 terlalu. Penyebab tidak langsung lainnya adalah ibu hamil menderita penyakit atau komplikasi lain yang sudah ada sebelum kehamilan, misalnya hipertensi, penyakit jantung, diabetes, hepatitis, anemia dan malaria. ${ }^{2}$

Tidak terdeteksinya resiko tinggi pada ibu hamil dan rujukan terlambat merupakan salah satu permasalahan utama dari terjadinya kematian ibu / bayi dengan segala permasalahan dasarnya baik dari aspek kesehatan maupun non kesehatan. Pendekatan Resiko pada ibu Hamil merupakan strategi operasional dalam upaya pencegahan terhadap kemungkinan kesakitan atau kematian melalui peningkatan efektifitas dan efisiensi dengan memberikan pelayanan yang lebih intensif kepada Resiko Ibu Hamil dengan cepat serta tepat, agar keadaan gawat ibu maupun bayi dapat dicegah. Pengenalan adanya Resiko Tinggi Ibu Hamil dilakukan melalui skrining/deteksi dini adanya faktor resiko secara proaktif pada semua ibu hamil, sedini mungkin pada awal kehamilan oleh petugas kesehatan. ${ }^{3}$

Menurut penelitian Rachel A Haws et al. (2009), dengan judul Screening and Monitoring During Pregnancy and Labor, mengidentifikasi tentang kehamilan resiko tinggi dan rendah penyebab kematian ibu dan bayi, serta memantau dan memilih melakukan perawatan tindak lanjut. Skrining dan pemantauan intervensi selama antenatal dan intrapartum dilakukan untuk mengetahui kesenjangan yang terjadi serta intervensi apa yang diperlukan untuk mengatasi masalah mortalitas dan morbiditas. Hasil penelitian ini menunjukkan effektif dalam mendeteksi masalah kesehatan pada saat kehamilan dan tindak lanjut setelah persalinan. ${ }^{4}$

Upaya meningkatkan kualitas pelayanan kebidanan juga ditentukan oleh ketrampilan bidan untuk berkomunikasi secara efektif dan melakukan konseling yang baik kepada klien. Sejauh ini metoda yang digunakan oleh petugas kesehatan adalah penyuluhan baik pada kunjungan kehamilan maupun kelas ibu 
hamil. Konseling masih sedikit digunakan dengan alasan waktu dan jumlah klien yang banyak. $^{5}$

Dalam penelitian Hanisa Putri dan Sulistyaningsih Tahun 2015, disebutkan bahwa konseling akan meningkatkan pengetahuan dan memperbaiki perencanaan persalinan dan pencegahan komplikasi sehingga diharapkan dengan pengetahuan yang dimiliki dapat direalisasikan rumah sakit sebagai tempat persalinan. Hal ini sejalan dengan tujuan penelitian bahwa dengan diberikannya konseling yang terfokus pada factor factor risiko kehamilan, ibu hamil dan keluarga dapat mengambil keputusan tempat persalinan yang tepat sehingga kematian ibu karena factor keterlambatan rujukan dapat dihindari. ${ }^{6}$

Dalam penelitian Sugiarti, Oedojo Soedirham, Imam S. Mochny tahun 2012 menyatakan bahwa lbu hamil dengan otonomi pribadi yang lebih baik akan mendeteksi risiko dan menilai kehamilan mereka serta dapat memilih institusi pelayanan kesehatan. Sehingga dapat berpengaruh terhadap upaya persiapan persalinan dan pemilihan tempat persalinan yang tepat serta upaya mengurangi kejadian rujukan terlambat. ${ }^{7}$

Berdasarkan data dari Dinas Kesehatan Kabupaten Tasikmalaya pada tahun 2017, kabupaten Tasikmalaya menempati urutan ke 4 AKI tinggi di Jawa Barat, dengan jumlah kematian ibu 37 dengan kejadian paling tinggi terdapat di Puskesmas Cikatomas 4 kematian dan Puskesmas Cisayong 3 kematian, dengan penyebab kematian diantaranya keterlambatan rujukan karena terlambat mengenali tanda bahaya dari pihak ibu hamil dan keluarga.

\section{METODE}

Design penelitian yang digunakan adalah Nonequivalent Control Group Design. Penelitian dilakukan pada dua kelompok ibu hamil yaitu: 1) Kelompok eksperimen dengan metode konseling individu, 2) Kelompok control dengan metode konseling kelompok (satu kelompok 5 orang ibu hamil).

Populasi penelitian adalah ibu hamil di wilayah Puskesmas Cikatomas dan
Puskesmas Cisayong. Sampel penelitian adalah Ibu hamil usia kehamilan $>32$ minggu. Total sampel 30 orang yang dibagi menjadi: 15 orang kelompok eksperimen, 15 orang kelompok kontrol. Penelitian dilaksanakan di wilayah Puskesmas Cikatomas dan Cisayong Kabupaten Tasikmalaya pada bulan Juni-Juli 2018.

Instrumen pengumpulan data menggunakan media putar penilaian faktor risiko kehamilan, lembar panduan konseling, kuesioner penilaian kemampuan deteksi dini dan kuesioner pelaksaanaan persiapan persalinan.

Analisis data terdiri dari: 1) Analisis univariat untuk menggambarkan variabel yang diteliti dengan rumus distribusi frekuensi, 2) Analisis bivariat menggunakan uji t test untuk data berdistribusi normal dan uji Wilcoxon untuk data tidak berdistribusi normal.

\section{HASIL}

Data penelitian terdiri dari pre test dan post test tentang kemampuan ibu hamil dalam melakukan deteksi dini factor risiko kehamilan dan persiapan persalinan sebelum dan sesudah mendapatkan konseling.

\section{Analisis Univariat}

Tabel 1: Kemampuan ibu Hamil dalam Melakukan Deteksi Dini Faktor Risiko Kehamilan sebelum dan sesudah konseling individu

\begin{tabular}{ccc}
\hline Penilaian & Pretest & Postest \\
\hline Mean & 36,6 & 42,8 \\
Median & 37,0 & 42,0 \\
Varians & 4,114 & 1,267 \\
Std Deviasi & 2,02837 & 1,12546 \\
Min-Maks & $33-39$ & $42-45$ \\
\hline
\end{tabular}

Hasil dari tabel 1 terdapat peningkatan rerata kemampuan ibu hamil dalam melakukan deteksi dini faktor risiko kehamilan yang terjadi dalam kehamilannya saat ini pada kelompok konseling individu 
Tabel 2: Kemampuan ibu Hamil dalam Melakukan Deteksi Dini Faktor Risiko Kehamilan sebelum dan sesudah konseling kelompok

\begin{tabular}{ccc}
\hline Penilaian & Pretest & Postest \\
\hline Mean & 35,93 & 41,40 \\
Median & 36,00 & 41,00 \\
Varians & 5,067 & 2,686 \\
Std Deviasi & 2,25093 & 1,63881 \\
Min-Maks & $32-40$ & $39-44$ \\
\hline
\end{tabular}

Hasil dari tabel 2 terdapat peningkatan rerata kemampuan ibu hamil dalam melakukan deteksi dini faktor risiko kehamilan yang terjadi dalam kehamilannya saat ini pada kelompok konseling kelompok

Tabel 3: Kemampuan ibu Hamil dalam Melakukan Persiapan Persalinan sebelum dan sesudah konseling individu

\begin{tabular}{ccc}
\hline Penilaian & Pretest & Postest \\
\hline Mean & 8,53 & 10,53 \\
Median & 9,00 & 11,00 \\
Varians & 0,838 & 0,267 \\
Std Deviasi & 0,91548 & 0,51640 \\
Min-Maks & $7-10$ & $10-11$ \\
\hline
\end{tabular}

Hasil dari tabel 3 terdapat peningkatan rerata kemampuan ibu hamil dalam melakukan persiapan persalinan pada kelompok konseling individu

Tabel 4: Kemampuan ibu Hamil dalam Melakukan Persiapan Persalinan sebelum dan sesudah konseling kelompok

\begin{tabular}{ccc}
\hline Penilaian & Pretest & Postest \\
\hline Mean & 8,27 & 10,07 \\
Median & 8,00 & 10,00 \\
Varians & 0,781 & 0,781 \\
Std Deviasi & 0,88372 & 0,88372 \\
Min-Maks & $7-10$ & $8-11$ \\
\hline
\end{tabular}

Hasil dari tabel 4 terdapat peningkatan rerata kemampuan ibu hamil dalam melakukan persiapan persalinan pada kelompok konseling kelompok

\section{Uji Normalitas Data}

Uji normalitas menggunakan rumus Kolmogorov-Smirnov

Tabel 5: Hasil Uji Normalitas

\begin{tabular}{|c|c|c|}
\hline Kelompok & Sig & Kesimpulan \\
\hline $\begin{array}{c}\text { Pre-Test } \\
\text { kemampuan deteksi } \\
\text { dini konseling } \\
\text { individu }\end{array}$ & 0,200 & $\begin{array}{l}\text { Terdistribusi } \\
\text { normal } \\
(\mathrm{N})\end{array}$ \\
\hline $\begin{array}{c}\text { Pos-Test } \\
\text { kemampuan deteksi } \\
\text { dini konseling } \\
\text { individu }\end{array}$ & 0,000 & $\begin{array}{l}\text { Terdistribusi } \\
\text { tidak normal } \\
\text { (TN) }\end{array}$ \\
\hline $\begin{array}{c}\text { Pre-Test } \\
\text { kemampuan } \\
\text { persiapan persalinan } \\
\text { konseling individu }\end{array}$ & 0,034 & $\begin{array}{l}\text { Terdistribusi } \\
\text { tidak normal } \\
\text { (TN) }\end{array}$ \\
\hline $\begin{array}{c}\text { Pos-Test } \\
\text { kemampuan } \\
\text { persiapan persalinan } \\
\text { konseling individu }\end{array}$ & 0,000 & $\begin{array}{l}\text { Terdistribusi } \\
\text { tidak normal } \\
\text { (TN) }\end{array}$ \\
\hline $\begin{array}{c}\text { Pre-Test } \\
\text { kemampuan deteksi } \\
\text { dini konseling } \\
\text { kelompok }\end{array}$ & 0,200 & $\begin{array}{l}\text { Terdistribusi } \\
\text { normal } \\
(\mathrm{N})\end{array}$ \\
\hline $\begin{array}{c}\text { Pos-Test } \\
\text { kemampuan deteksi } \\
\text { dini konseling } \\
\text { kelompok }\end{array}$ & 0,200 & $\begin{array}{l}\text { Terdistribusi } \\
\text { normal } \\
\text { (N) }\end{array}$ \\
\hline $\begin{array}{c}\text { Pre-Test } \\
\text { kemampuan } \\
\text { persiapan persalinan } \\
\text { konseling kelompok }\end{array}$ & 0,052 & $\begin{array}{l}\text { Terdistribusi } \\
\text { normal } \\
(\mathrm{N})\end{array}$ \\
\hline $\begin{array}{c}\text { Pos-Test } \\
\text { kemampuan } \\
\text { persiapan persalinan } \\
\text { konseling kelompok }\end{array}$ & 0,004 & $\begin{array}{l}\text { Terdistribusi } \\
\text { tidak normal } \\
\text { (TN) }\end{array}$ \\
\hline
\end{tabular}

Hasil tabel 5 data pre-test dan pos test berdistribusi normal terdapat 4 kelompok data dan data yang berdistribusi tidak normal terdapat 4 kelompok data.

\section{Analisis Bivariat}

Analisis yang digunakan adalah uji Wilcoxon untuk data yang tidak berdistribusi normal dan uji t untuk data yang berdistribusi normal, sebagai berikut : 
1. Uji Wilcoxon PreTest dan PosTes Kemampuan Melakukan Deteksi Dini Pada Konseling Individu, Hasil uji didapatkan nilai $p<0,05$ yaitu $(0,001)$, yang berarti dapat disimpulkan terdapat pengaruh yang signifikan pada skor Kemampuan Melakukan Deteksi Dini kehamilan berisiko Pada Konseling Individu

2. Uji Wilcoxon PreTest dan Pos Tes Kemampuan Melakukan Persiapan Persalinan Pada Konseling Individu, Hasil uji didapatkan nilai $p<0,05$ yaitu $(0,001)$, yang berarti dapat disimpulkan terdapat pengaruh yang signifikan pada skor Kemampuan Melakukan Persiapan Persalinan Pada Konseling Individu

3. Uji t PreTest dan Pos Tes Kemampuan Melakukan Deteksi Dini Pada Konseling Kelompok, Hasil uji t berpasangan didapatkan nilai $P<0,05(0,000)$ yang berarti dapat disimpulkan terdapat peningkatan secara signifikan pada skor Kemampuan Melakukan Deteksi Dini Pada Konseling Kelompok

4. Uji Wilcoxon PreTest dan Pos Tes Kemampuan Melakukan Persiapan Persalinan Pada Konseling Kelompok, Hasil uji didapatkan nilai $p<0,05$ yaitu $(0,001)$, yang berarti dapat disimpulkan terdapat pengaruh yang signifikan pada skor Kemampuan Melakukan Persiapan Persalinan Pada Konseling kelompok.

\section{PEMBAHASAN}

Dari hasil penelitian diperoleh bahwa rata-rata kemampuan melakukan deteksi dini factor risiko kehamilan pada kelompok sebelum dilakukan konseling individu adalah 36,6 dan sesudah menjadi 42,8 . Terdapat peningkatan skor sebanyak 6,2. Konselingadalah upaya menggali dan memberikan informasi guna mendapatkan apa yang dibutuhkan dan membantu ibu hamil dalam mengambil keputusan. ${ }^{8}$

Carl $R$ Rogers menyatakan bahwa manusia adalah pribadi pribadi yang memiliki potensi untuk memecahkan permasalahannya sendiri. Carl $R$ Rogers mengembangkan pendekatan client-centered dalam konseling untuk diaplikasikan pada kelompok, keluarga, masyarakat dan terlebih kepada individu. ${ }^{9}$

Konseling individual merupakan proses belajar yang bertujuan agar konseli dapat mengenal diri sendiri, menerima diri sendiri serta realistis dalam proses penyesuaian dengan lingkungan, membantu individu membuat keputusan, pemilihan dan rencana yang bijaksana. ${ }^{10}$

Prayitno (1995) dalam Penelitian Sari, Yusmansyah dan Utaminingsih (2013) tentang implementasi konseling kelompok menjelaskan bahwa di dalam konseling kelompok individu dapat mengembangkan kemampuan berkomunikasi serta menerima dan menyampaikan pendapat secara logis, efektif dan produktif, kemampuan bertingkah laku dan berinteraksi sosial. ${ }^{11}$

Kehamilan dapat menimbulkan komplikasi yang dapat mengancam jiwa ibu maupun bayi sehingga di dalam setiap kunjungan antenatal ibu hamil perlu mendapatkan informasiinformasi penting tentang kehamilannya agar dapat diidentifikasi sedini mungkin adanya komplikasi. Either mengatakan bahwa identifikasi komplikasi pada ibu hamil dapat dilakukan dengan konseling selama kehamilan. Hal ini didukung oleh Obermeyer yang mengatakan bahwa konseling yang diberikan dalam bentuk informasi dapat membantu klien dalam mengenali resiko yang ada dalam dirinya. ${ }^{8}$

Strategi pendekatan risiko atau Risk Approach Strategy dikembangkan dalam upaya untuk penanganan ibu hamil berisiko. Adanya kerentanan terhadap penyakit atau kelainan pada ibu hamil disebabkan mereka mempunyai berbagai karakteristik atau faktor risiko yang satu sama lain saling berpengaruh. Faktor risiko ini bisa bersifat biologis, genetik, lingkungan atau psikososial. Sebagian dari faktor risiko ini dapat dikenal dan diukur sehingga kita dapat menggunakannya dalam upaya pelayanan kesehatan preventif. Untuk kepentingan managemen, kumpulan faktor risiko itu dapat diubah dalam bentuk scores yang dapat diukur dan dipakai untuk memperkirakan besar dan jenis kebutuhan pelayanan. Sekarang strategi pendekatan risiko dianggap sebagai suatu alat manajemen dengan menggunakan faktor risiko atau 'scores' sebagai salah satu pedoman untuk 
pelaksanaan rujukan. Wacana inilah yang menjadi pegangan dasar bahwa strategi pendekatan risiko bila dilakukan secara konsisten akan dapat memperbaiki derajat kesehatan reproduksi, khususnya di negara yang sedang berkembang, termasuk Indonesia. ${ }^{12}$

Kehamilan berisiko dapat meningkatkan ketakutan dan kecemasan pasangan pada saat menjelang persalinan. Komunikasi, kontrol, dan deteksi dini yang efektif adalah alat penting yang harus dapat dipastikan oleh wanita untuk merencanakan strategi perawatan terbaik dan meminimalkan risiko ibu dan atau janin. ${ }^{13}$

Dari hasil penelitian diperoleh bahwa rata-rata kemampuan melakukan persiapan persalinan pada kelompok sebelum dilakukan konseling individu adalah 8,53 dan sesudah menjadi 10,53 . Terdapat peningkatan skor sebanyak 2.

Salah satu upaya yang dapat dilakukan bidan bersama pasangan dalam membuat perencanaan persalinan melalui fasilitasi kelas antenatal, menyediakan lebih banyak waktu bagi pasangan/calon orangtua untuk berbicara satu sama lain. ${ }^{14}$

Berdasarkan hasil penelitian Montung, Adam, Manueke (2016) menyebutkan bahwa dari hasil wawancara yang dilakukan pada 12 ibu hamil yang datang memeriksakan kehamilannya di Puskesmas Danowudu ditemukan 9 ibu hamil yang belum mengetahui persiapan yang harus dilakukan menjelang persalinan, 3 ibu hamil mengatakan persiapan persalinan yang terpenting adalah persiapan kebutuhan bayi baru lahir. Persiapan persalinan yang direncanakan bersama bidan diharapkan dapat mengurangi ketidaksiapan ibu saat persalinan dan meningkatkan kemungkinan ibu akan menerima asuhan yang optimal. ${ }^{15}$

Dari hasil penelitian diperoleh bahwa rata-rata kemampuan melakukan deteksi dini factor risiko kehamilan pada kelompok sebelum dilakukan konseling kelompok adalah 35,9 dan sesudah menjadi 41,4. Terdapat peningkatan skor sebanyak 5,5.

Melalui proses konseling menjadi salah satu upaya meningkatkan pemberdayaan perempuan dalam kesehatan. Pemberdayaan diakui secara luas sebagai proses untuk meningkatkan self efficacy mereka dan membuat keputusan yang meningkatkan kehidupan. Sebagian besar negara sekarang mengakui pentingnya perempuan untuk menjadi lebih berdaya, baik untuk dirinya sendiri ataupun untuk mencapai keadilan dan kesetaraan gender. Pemberdayaan secara langsung atau tidak langsung mempengaruhi berbagai aspek kesehatan wanita. Dalam beberapa konteks, perawatan antenatal kelompok dapat lebih memberdayakan perempuan disebabkan karena dapat meningkatkan komunikasi dan pembelajaran antar kelompok. Wanita hamil yang merasa diberdayakan melalui keterampilan koping yang lebih baik sebelum kelahiran diasumsikan kecil kemungkinan menderita depresi pascapersalinan. ${ }^{16}$

Kehamian dan menjadi ibu adalah fenomena fisiologis. Namun sekitar 830 wanita meninggal karena sebab yang dapat dicegah terkait dengan kehamilan dan persalinan. Konseling persiapan persalinan dan pencegahan komplikasi merupakan upaya preventif yang dapat dilakukan juga dengan meningkatkan pengetahuan ibu hamil tentang tanda bahaya kehamilan dan persalinan. Dalam penelitian ditemukan bahwa $58,5 \%$ wanita melakukan persiapan persalinan dengan baik. Pendidikan, pekerjaan, status sosial ekonomi berhubungan signifikan dengan pelaksanaan persiapan persalinan. ${ }^{17}$

Persiapan persalinan dan pencegahan komplikasi adalah strategi komprehensif untuk meningkatkankesejahteraan ibu dan janin. Memberikan pendidikan, pengetahuan dan keterampilan kepada perempuan dan meningkatkan peran mereka dalam pengambilan keputusan sangat penting untuk meningkatkan pelaksanaan persiapan persalinan dan pencegahan komplikasi dalam kehamilan yang harus difasilitasi bidan baik dalam asuhan individu, kelompok dan di komunitas. ${ }^{17}$

Dalam penelitian ini konseling kelompok dilakukan dalam pelaksanaan kelas ibu hamil. Kelas ibu hamil merupakan sarana untuk belajar bersama tentang kesehatan bagi ibu hamil, dalam bentuk tatap muka dalam kelompok yang bertujuan untuk meningkatkan pengetahuan dan keterampilan ibu-ibu mengenai kehamilan, persalinan, perawatan 
nifas, perawatan bayi baru lahir, mitos dan penyakit menular.

Dari hasil penelitian diperoleh bahwa rata-rata kemampuan melakukan persiapan persalinan pada kelompok sebelum dilakukan konseling kelompok adalah adalah 8,27 dan sesudah menjadi 10,06. Terdapat peningkatan skor sebanyak 1,79.

Persiapan persalinan adalah usaha ibu hamil untuk menghadapi kelahiran bayi yang meliputi persiapan fisik, mental (psikologis) dan materi yang cukup agar kelahiran anak berjalan dengan lancar, menghasilkan ibu dan anak yang sehat. Persiapan persalinan difokuskan pada ibu hamil trimester III karena merupakan persiapan aktif menunggu kelahiran bayi dan menjadi orang tua. ${ }^{18}$

Hasil analisis bivariat diperoleh bahwa terdapat pengaruh yang signifikan konseling individu dan konseling kelompok terhadap peningkatan kemampuan ibu hamil melakukan deteksi dini factor risiko kehamilan dan dapat meningkatkan kemampuan ibu hamil dalam melakukan persiapan persalinan.

Dari hasil penelitian diperoleh bahwa sebagian besar responden mengemukakan baru mengetahui system scoring penilaian factor risiko kehamilan, dan bidan belum optimal melaksanakan konseling factor risiko ini baik pada saat melakukan kunjungan ANC secara individu maupun dalam kegiatan kelas ibu hamil.

Bidan mengemukakan perlu adanya media tambahan untuk digunakan dalam konseling factor risiko ini, dan berharap ibu hamil dapat melakukan self assessment dan dapat menentukan / memilih tempat dan penolong persalinan yang tepat, maka diperlukan upaya sosialisasi dan pendidikan yang lebih intensif di lapangan.

Berdasarkan keterangan Bidan, scoring factor risiko ini sudah ada dalam Buku KIA akan tetapi pelaksanaannya belum optimal, karena masih ada bidan yang belum melakukan konseling ini menggunakan Buku $\mathrm{KIA}$. Belum terdapat aturan atau penyeliaan untuk tenaga kesehatan dari Dinas Kesehatan dalam mengoptimalkan penggunaan system scoring ini di lapangan.

\section{SIMPULAN DAN SARAN}

\section{Simpulan}

1. Terdapat pengaruh yang signifikan pada skor Kemampuan Melakukan Deteksi Dini kehamilan berisiko Pada Konseling Individu

2. Terdapat pengaruh yang signifikan pada skor Kemampuan Melakukan Persiapan Persalinan Pada Konseling Individu

3. Terdapat pengaruhyang signifikan pada skor Kemampuan Melakukan Deteksi Dini Pada Konseling Kelompok

4. Terdapat pengaruh yang signifikan pada skor Kemampuan Melakukan Persiapan Persalinan Pada Konseling kelompok.

\section{Saran}

1. Penilaian/Skoring factor risiko kehamilan diharapkan dapat disosialisasikan kepada masyarakat karena sangat berhubungan dengan pemilihan tempat dan penolong persalinan.

2. Setiap bidan baik di komunitas maupun di Puskesmas dan Rumah Sakit agar melakukan konseling factor risiko kehamilan dan mematuhi hasil penilaian yang didapat agar pelayanan bidan sesuai dengan standar

3. Diharapkan Dinas Kesehatan menetapkan kebijakan penapisan risiko kehamilan agar dilaksanakan dilapangan karena sangat membantu proses pelaksanaan kegiatan rujukan terencana sehingga diharapkan kematian ibu karena faktor keterlambatan dapat diminamilisir atau tidak terjadi

\section{DAFTAR PUSTAKA}

1. Kementerian Kesehatan Republik Indonesia. Rencana strategis kementerian kesehatan tahun 2015-2019. Jakarta: Kemenkes; 2015

2. Widiastuti T, Kartasurya M, Dharminto D. Management of highrisk pregnancy early detection on antenatal care at primary health care in jepara district. Jurnal Managemen Kesehatan Indonesia Vol 2 No 3: FKM UNDIP; 2016 
3. Idhayanti Itha R, Masini, Sarwono B. Dukungan keluarga berpengaruh terhadap skrining antenatal bidan desa. Jurnal Kebidanan Vol 5 No 10: Poltekkes Semarang; 2016.

4. Haws A Rachel, Yakoob Yawar M, Soomro T, Menezes Esme V, Darmstadt Gary L, Bhutta Zulfikar A. Reducing stillbirth screening and monitoring during pregnancy and labour [Internet]. BMC Pregnancy and Childbirth 20099 (Suppl 1): S5. Available from https://bmcpregnancychildbirth.biomedce ntral.com

5. Yahya, Safira Shinta, Suharni. Pengaruh penyuluhan tanda bahaya kehamilan terhadap tingkat pengetahuan ibu primigravida di puskesmas mergangsan yogyakarta [thesis]. Yogyakarta: Universitas Aisyiyah Yogyakarta; 2017

6. Putri, Hanisa, Sulistyaningsih. Pengaruh konseling terhadap pengetahuan, perencanaan persalinan dan pencegahan komplikasi ibu hamil berisiko di puskesmas pundong bantul [thesis]. Yogyakarta: Universitas Aisyiyah Yogyakarta; 2015

7. Sugiarti, Soedirman Oedojo, Mochny Imam S. Upaya pemberdayaan ibu hamil untuk deteksi dini risiko tinggi kehamilan trimester satu. The Indonesian Journal of Public Health Vol. 9 - No. 1: Departemen Promosi Kesehatan dan IImu Perilaku Fakultas Kesehatan Masyarakat Universitas Airlangga; 2012

8. Heru Retno, Hasanbasri Mubasysyir, Hakimi Mohammad. Konseling ibu hamil pada bidan praktik swasta dan puskesms di kabupaten bantul. Jurnal Kebijakan Kesehatan Indonesia JKKI Vol 1 No 3: Universitas Gadjah Mada; 2012

9. Lumongga Namora. Memahami dasar dasar konseling dalam teori dan praktek. Jakarta: PT Kharisma Putra Utama Kencana Prenadamedia grup; 2014

10. Hartini Nurul, Ariana Atika Dian. Psikologi konseling perkembangan dan penerapan. Jakarta: Airlangga University Press; 2016

11. Sari Yulia Malida, Yusmansyah, Utaminingsih Diah. Penggunaan layanan konseling kelompok. ALIBKIN (Jurna Bimbingan Konseling) Vol 2 no 4: Universitas Lampung; 2013
12. Dwiaryana Made Bagus. Strategi pendekatan risiko dan sistem rujukan kasus obstetri. Denpasar: Divisi obstetri ginekologi sosial Bagian/SMF Obgin FK UNUD/RSUP Sanglah Denpasar; 2012

13. Coco L, Giannone T. T, Zarbo G. Management of high-risk pregnancy. Edizioni Minerva Medica Journals and Books on medicine August;66(4):383-9; 2014

14. Barimani $M$, Forslund Frykedai $K$, Rosander M, Berlin A. Childbirth and parenting preparation in antenatal class [Internet]. Journal Midwife. Available form https://www.ncbi.nlm.nih.gov/pubmed/291 28739; 2017

15. Montung VL, Adam SK, Manueke I. Hubungan pengetahuan dengan perilaku ibu hamil trimester III dalam persiapan persalinan. Jurnal IImiah Bidan 4 (1); 2016

16. Ndola Prata, Paula Tav Row, Ushma Upadhyay. Women's empowerment related to pregnancy and childbirth [Internet]. BMC Pregnancy ChildBirth. Available form https://www.ncbi.nlm.nih.gov/pmc/articles/ PMC5688486/ ; 2017

17. Sharma N, Kumar N, Singh S, Malik JS, Jangra A. Status and determinants of birth preparedness and complication readiness in a rural block of harvana [interet]. J Family Med Prim care Feb;8(2):482-486. Avaliable from https://www.ncbi.nlm.nih.gov/pubmed/309 84659; 2019

18. Lucia Sorongan, Purwandari Atik, Pesak Ellen. Pengaruh pelaksanaan kelas Ibu hamil terhadap pegetahuan tentang persiapan persalinan. JIDAN (Jurnal IImiah Bidan): Poltekkes Kemenkes Manado; 2015 